\title{
Juego de Arena y Escrituras de Sí: revelando los itinerarios ecoformativos de una profesora
}

\section{The Sandplay and the Written of Itself: revealing the eco-formative journey of an teacher}

Luciane Schulz postdoctoranda en el Programa de Post Graduación en Educación de la Universidad Regional de Blumenau (Brasil) (luciane.schulz19@gmail.com) (http:/orcid.org/0000-0003-1662-6633)

Recibido: 2017-08-01 / Revisado: 2017-10-09 / Aceptado: 2017-11-06 / Publicado: 2018-01-01

\section{Resumen}

Los estudios apuntan que el foco central que permea los cursos de formación de profesores está en una concepción esencialmente intelectual/conceptual. Por otro lado es necesario dar voz a este profesor en formación, con la creación de un ambiente pedagógico que favorezca la autoría, la autoconstrucción y la autorreflexión en el sentido de su subjetividad. Este artículo parte del referencial (auto)biográfico que se caracteriza como la búsqueda de la comprensión de sí mismo y de sus relaciones con el saber y tiene como objetivo presentar el itinerario de la ecoformación de la autora, por medio de la descripción y el análisis del Juego de Arena (Sandplay) y de las escrituras de sí. La metodología consistió en talleres que se realizaron en el Programa de Postgrado de Maestría y Doctorado del Centro de Educación de la Universidad Federal de Rio Grande do Norte, Brasil, culminando con la confección de escenarios imaginarios de los elementos agua, fuego, aire y tierra por medio del Juego de Arena y de las escrituras de sí. Esta apertura dada para la investigación (auto)biográfica y el Juego de Arena como recursos metodológicos autorreflexivos nos hizo tomar conciencia de que la ecoformación ha sido el motor inductor de toda nuestra trayectoria personal, docente y académica. Por lo tanto, el Juego de Arena y las escrituras de sí, son recursos metodológicos ecoformativos esenciales para la formación del profesor.

Descriptores: Búsqueda (auto)biográfica, ecoformación, Escrituras de sí, formación del profesor, Juego de arena (Sandplay), profesora.

\begin{abstract}
Some studies point out that the central focus that permeates teacher training courses is in an essentially intellectual / conceptual conception. On the other hand, it is necessary to give voice to this teacher in formation, with the creation of an educational environment that favors authorship, self-construction and self-reflection in the sense of their subjectivity. This article starts with the (Auto)biographic referential that
\end{abstract}

Forma sugerida de citar: Schulz, L. (2018). Juego de Arena y Escrituras de Sí: revelando los itinerarios ecoformativos de una profesora. Alteridad, 13(1), 132-145. https://doi.org/10.17163/alt.v13n1.2018.10. 
is characterized as the search for the understanding of oneself and for its relations with the knowledge and aims to present the author's eco-formative journey through the description and analysis of the Sandplay and the Written of itself.The methodology consisted of workshops that were carried out in the Postgraduate Program of the Education Center of the Universidade Federal do Rio Grande do Norte, culminating in the creation of imaginary scenarios of water, fire, air

\section{Introducción}

En programas de formación de profesores, se percibe la ausencia de la dimensión personal, que es una cuestión frecuentemente señalada por algunos estudiosos e investigadores del área educacional (Gatti, 2003; Placco, 2002; Nóvoa, 2009). El enfoque central que está presente en tales estudios es la visión orientada esencialmente por los aspectos intelectuales y conceptuales de gran parte de esos cursos de formación.

O sea, tales estudios parten del presupuesto de que cuánto más grande es la oferta de informaciones y contenidos, más grandes serán los cambios en sus posturas y formas de actuar, a partir del dominio de nuevos conocimientos. Los profesores, por otra parte, no son percibidos por sus subjetividades, ${ }^{1}$ las cuales los constituyen como individuos frente a los múltiples efectos de las dinámicas de sus condiciones sociales y afectivas, sus pensamientos y sus emociones. Según Gatti (2003) y Scoz (2011), esa situación puede ser una de las razones por las cuales tantos programas de formación inicial y continuada de docentes, que buscan cambios cognitivos, de metodologías y de posturas, se revelan insatisfactorios, sin resultados eficientes.

Es necesario poner más atención a las concepciones metodológicas presentes en esos cursos de formación. O sea, es necesario entender la importancia de que se creen espacios sanos, que valoren y discutan el rol de la emoción y de los sentimientos. Como indica Maturana y VerdenZöller (2011), espacios donde se corrija el hacer, y no el ser, donde se contemplen metodologías de and earth elements through the Sandplay and the Written of itself. This openness given through these methodological resources has made us aware that eco-formation has been the motto of our entire personal, academic and academic trajectory. Therefore, the Sandplay and the written of itself, are eco-formative methodological resources essential for teacher training. Keywords: Autobiographic Research, eco-formation, Sandplay, teacher training, Written of itself, teacher.

autorreflexividad que conduzcan a su proceso de (auto-hetero-eco)formación ${ }^{2}$ (Pineau, 2008a).

En la búsqueda por esas experiencias de formación o aún por esos ambientes de ecoformación, ya sean formales, informales o no formales, nos apoyamos en la investigación (Auto) biográfica, considerando que "Autos es la identidad, lo yo que es consciente de sí mismo, Bios es la vida simplemente vivida y la Grafia es el medio para un nuevo nacimiento del yo, refiriéndose al arte profesional de tejer una figura pública de sí" (Passeggi, 2008, p. 28). En otras palabras, se caracteriza como la búsqueda de la comprensión de sí mismo y de sus relaciones con el saber.

La metodología de ese estudio se creó en el "Seminário Expressividade e Corporeidade", realizado en la BACOR ("Base de Pesquisa da Corporeidade") del PPGE (el Programa de Postgrado en Educación) de la Universidad Federal del Rio Grande do Norte, ${ }^{3}$ con alumnos de los programas de maestría y doctorado en el año de 2009. Sus objetivos eran profundizar los estudios de la Pedagogia Vivencial Humanescente (Cavalcanti, 2010). El punto culminante de ese coloquio fue la creación de escenarios imaginarios tridimensionales de los elementos agua, fuego, aire y tierra a través del Juego de Arena y de las escrituras de sí. ${ }^{4}$

El Juego de Arena, defendido en investigaciones realizadas por Ammann (2004), Cavalcanti (2010), Scoz (2011) y Schulz (2014), es una herramienta que estimula los juegos durante su ejecución, asociados al proceso de creación, desarrollando de esta forma la autorreflexividad de los participantes de la actividad. Las 
escrituras de sí (Passeggi, 2010), por su parte, son un dispositivo que produce el autorreflexión, la expresión y la resignificación de lo que se siente, de lo que se hace y de lo que se piensa a través de lo que se escribe.

En conformidad con el cuadro expuesto, el objetivo de este artículo es presentar la trayectoria ecoformativa de la autora a través de la investigación (Auto)biográfica y del Juego de Arena, respectivamente en cuanto recursos epistemológico y metodológico autorreflexivos. Utilizaremos como base para este trayecto los cuatro elementos de la naturaleza (agua, fuego, tierra y aire), apoyándonos en Bachelard (2001; 2003; 2008; 2013).

\section{Investigación (auto)biográfica y las Escrituras de Sí}

Para pensar y escribir dentro de un enfoque epistemológico y metodológico de la investigación (auto)biográfica, que por su parte contribuye con el movimiento de las escrituras de sí, de las historias de vida, del caminar hacia uno mismo, de la (auto-hetero-eco) formación, utilizamos como base los estudios de Gaston Pineau, en Canadá, Marie-Christine Josso, en Suiza, y António Nóvoa, en Portugal (Passegi, 2010).

Al llevar a alguien que escribe a reflexionar, a expresar y a resignificar lo que siente, lo que hace y lo que piensa, tenemos en las propias escrituras de sí un dispositivo que posibilita el enriquecimiento del repertorio de la "persona común", redimensionando el rol atribuido al sujeto. O sea, tenemos un lugar de reconstrucción del saber profesional y de identidad. (Passeggi, 2010).

Según la autora (2008), hay tres etapas que forman las escrituras de sí: la primera es la evocación de los recuerdos; la segunda es un momento intermediario de reflexión, en el cual el narrador se interroga y toma conciencia de las experiencias formadoras; en la tercera, reconoce a sí mismo como un otro y por el otro, el punto de llegada de una nueva partida.
Los docentes, cuando escriben sobre su vida, ejercitan el saber analizar y el analizarse. De esta forma, reflexionan y son desafiados a "reconstruir el conocimiento profesional a partir de una reflexión práctica y deliberada" (Nóvoa, 2002 , p. 27), porque es imposible separar la dimensión personal de la profesional. Eso exige un "análisis interpretativo de los acontecimientos en el contexto de su ocurrencia y la ecología de sus relaciones" (Nóvoa, 2002, p. 41), visto que el ejercicio de la profesión ocurre no solamente a través del cúmulo de saberes y competencias, sino también a través de la forma como son aplicados en una determinada situación pedagógica para promover un aprendizaje significativo.

El desarrollo de la dimensión personal en programas de formación de profesores otorga voz a los protagonistas acerca de la acción educativa. En contrapartida, existe la concepción específicamente orientada por los aspectos intelectuales y conceptuales de la mayoría de esos cursos de formación, con énfasis en el enfoque tecnicista de enseñar y también fragmentada al discutir la relación del individuo con los conocimientos producidos para su (hetero-eco) formación y con él mismo para su (auto)formación. Por eso es importante contemplar las escrituras de sí para la investigación de las relaciones establecidas entre la experiencia y el proceso de formación inicial y continuada del profesor, construyendo un conocimiento de sí mismo que surge del conocimiento en cuanto profesional que no se completa solamente con enfoques de carácter técnico y científico.

\section{Juego de Arena (Sandplay): un recurso tecnológico reflexivo}

El Juego de Arena (Ammann, 2004; Cavalcanti, 2010; Scoz, 2011) es un recurso de carácter investigativo que tuvo como su pionera, entre los años 1954 y 1956, a la analista suiza junguiana Dora Kalff (1980). Según Ammann (2004) es un método basado en la creación práctica y creativa en la 
caja de arena. Para la realización del juego, hay una caja con arena que forma el campo concreto. Su tamaño es de aproximadamente 17x50x07 $\mathrm{cm}$, para que esté dentro del campo visual del participante sentado frente a la caja.

Para la construcción de los escenarios imaginarios, o sea, uno de los productos del Juego de Arena, se ofrece una colección de miniaturas de varios materiales, como arcilla, madera, plástico, fibras naturales, entre otros, como se puede observar en la Figura 1A. Para intentar condensar y enriquecer los valores, los temas de problematización aplicados al Juego de Arena, las miniaturas son lo más variadas posible, obedeciendo a demandas universales y multiculturales (Cavalcanti, 2010; Schulz, 2014). No obstante, en caso de que no sea posible encontrar todas las figuras que se deseen para la simbolización, no hay problema, visto que eso es lo que estimula la creación del propio participante. Así que, a través de diversos objetos y miniaturas que incluyen representaciones realistas de animales, materiales de profesiones, medios de transporte, construcciones, árboles, flores, figuras humanas, entre otros, ocurre el encuentro simbólico, desvelando experiencias y descubiertas significativas, visto que "los que juegan en la caja de arena, ya sean adultos o niños, crean varias imágenes tridimensionales en la arena, involucrándose en ese proceso en cuerpo, alma y espíritu" (Ammann, 2004, p. 11). Las miniaturas deben ser de buena calidad para que sean atractivas y estimulen el sentido estético y creativo del sujeto de la investigación.

Para Weinrib (1993, p. 37), el concepto de "espacio libre y protegido" es el aspecto central del Juego de Arena, que tiene dimensiones tanto físicas como psicológicas, puesto que, por un lado, hay la posibilidad de crear lo que se desee en la caja de arena, pero, por otro lado, su tamaño y el número de miniaturas, aunque sean variados, son limitados y "constrictivos". Así se crea una situación segura y protegida.

El punto de partida surge a partir de una pregunta-problema. Los sujetos de la investiga- ción, sentados en círculo, como se puede observar en la Figura 1B, crean en la caja de arena escenarios imaginarios tridimensionales que respondan a la pregunta-problema. En ese momento, "predomina la acción y se habla poco, principalmente de modo no inmediato o de manera racional e interpretativa" (Ammann, 2004, p. 23), y al componer el escenario, lo que se ofrece es un constante retrato del estado emocional en un claro espejo de su desarrollo analítico (Weinrib, 1993), puesto que son representadas figuras y paisajes del mundo interior y exterior.

En la segunda etapa de la actividad, hay la descripción oral por parte del sujeto de la simbología de cada parte del escenario, momento en el cual ocurre la reflexión sobre el proceso creativo, porque "primero se vive, se experimenta, se elabora y después se nombra y se proclama" (Gadotti, 2000, p. 94). El objetivo de esta etapa es establecer conexiones con uno mismo (autoformación), con el otro (heteroformación) y con los saberes del mundo (ecoformación). Los participantes forman un círculo porque, según Tuan (2012), el círculo es el símbolo junguiano que otorga reconciliación de los opuestos para que se obtenga la totalidad y la harmonía.

Según Weinrib (1993), en esa segunda etapa de exhibición y explicación individual del escenario, es posible concretizar más la experiencia con el inconsciente, porque el impacto sobre el participante que socializa provoca reflexiones y cambios. De la misma forma, los participantes que escuchan son afectados, reconociendo las conexiones de los significados simbólicos de los escenarios con ellos mismos. Para futura análisis y manejo de los datos que surgen durante la vivencia a través del habla reflexiva de los participantes, son importantes los registros en forma de audio, producido durante la socialización de cada escenario, y en forma imaginaria, a través del registro fotográfico de las imágenes creadas, produciéndose posteriormente un archivo que debe ser organizado en forma de portafolio con las representaciones más significativas del momento. 
a) Miniaturas ofrecidas

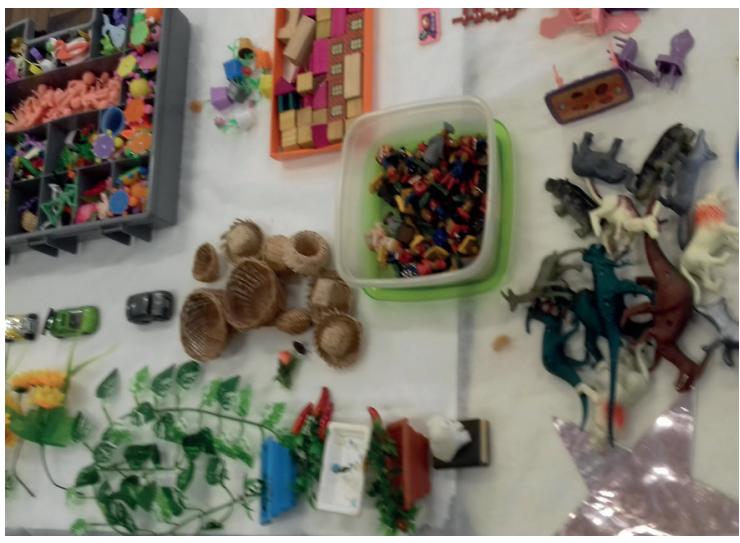

b) Momento vivencial en el Juego de Arena

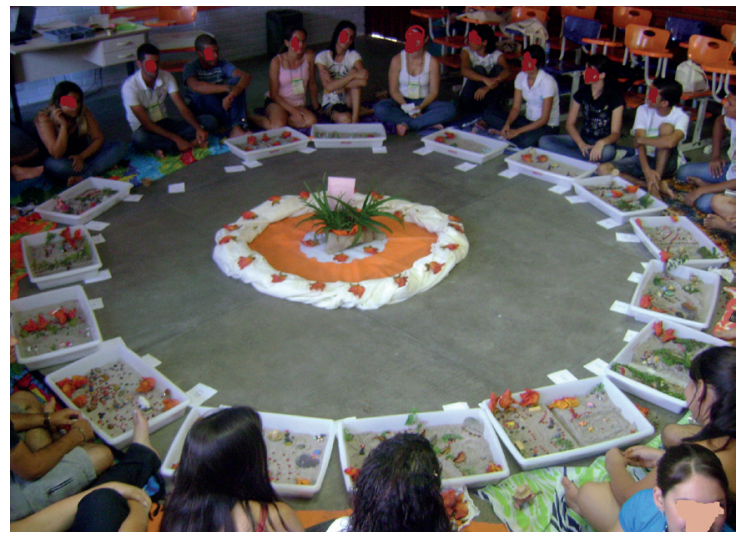

\section{Trayecto Ecoformativo a través del Juego de Arena y de las Escrituras de sí}

Al iniciar una investigación que terminaría en la defensa de la tesis de doctorado intitulada "Pedagogía Ecovivencial Ambiental -por una Educación Ambiental Emancipatoria" (Schulz, 2014), sentimos la necesidad de reflexionar sobre nuestra propia existencia. Durante nuestro desarrollo, desde de la infancia hasta la edad adulta, ya sea en el campo personal o profesional, el proceso ecoinformativo ha sido estimulado, despertando la inquietud para la investigación y la profundización de esa temática. Pero la toma de conciencia de ese trayecto ecoinformativo ocurrió con la participación como alumna con vinculación especial de la BACOR, en 2009.

El punto culminante de ese coloquio fue la creación de escenarios imaginarios tridimensionales de los elementos agua, fuego, aire y tierra a través del Juego de Arena, representados en las Figuras 2, 3, 4 e 5, siendo la pregunta problematizadora para cada encuentro la siguiente: ¿Cuál es el recuerdo más destacado de mi relación con los elementos agua, fuego, tierra y aire? El coloquio estuvo dividido en secciones que contemplaban un elemento a la vez.

Ahora, de acuerdo con el referencial adoptado en este texto, el cual discute las escrituras de sí en cuanto un recurso de la investigación (Auto)biográfica, describiremos nuestro trayecto ecoformativo. Con el auxilio del Juego de Arena, muchos recuerdos afloraron, y con ellos las marcas, algunas buenas y otras ni tanto, que han contribuido para nuestro proceso de ecoformación.

Por haber vivido en una casa con patio en un medio urbano, pero que tenía características campesinas, nuestros aspectos cognitivos, afectivos y emocionales eran estimulados, en un proceso ecoformativo (Pineau, 2004; 2008a; 2008b, 2010, 2012), visto que podía disfrutar libremente de ese ambiente. Esa ecovivencialidad ${ }^{5}$ (Schulz, 2014) ha posibilitado, desde la infancia, la percepción de nuestro entorno ambiental por sus diversas formas de expresión, como: los sonidos de los árboles provocados por la lluvia; el crepúsculo por detrás de la montaña; el canto de los pájaros al amanecer.

Compartía ese ambiente ecoformador con personas creadas con ecovivencias y saberes del campo, una familia urbana, pero con esencia campesina. Así, la biodiversidad estaba presente 
bajo la forma de canes, gallinas, diversos tipos de pájaros, árboles frutales y un huerto, que enseñaban a mantenerse sano y en conexión y harmonía con la tierra. Y todas las mañanas observábamos la vida que se renovaba mientras caminábamos por ese "patio encantado", 6 estimulando todos nuestros sentidos a través de colores, sonidos, olores y sabores. Era un aprendizaje constante poder vivenciar esa realidad concreta, en el sentido de la ecoformación en conformidad con las lecturas de mundo propuesta por Freire (2012).

Al compartir con un grupo de amigos un entretenimiento en común, buscando renovar las energías en otros "patios encantados" durante la juventud, hacíamos largas caminatas por el bosque. Veíamos lindas cascadas, y ahí nos bañábamos, porque el agua tiene el poder de llevarnos, de arrullarnos, de adormecernos (Bachelard, 2013).
Al buscar los recuerdos lúdicos de la adolescencia con el elemento agua, nos valemos de Bachelard (2013, p. 9) y sus devaneos afirmando que "no puedo sentarme cerca de un regato sin que se produzca en mí un devaneo profundo, sin que contemple mi fortuna".

La práctica del Juego de Arena permite una expresión tangible tridimensional de los contenidos incipientes e inconscientes, puesto que, como podemos percibir, la preparación del escenario es, en sí misma, un acto simbólico, y los símbolos son representados por las construcciones, que por su parte representan figuras y paisajes del mundo interior y exterior. Así, "al bañarse en agua fresca para renacer renovado" (Bachelard, 2013, p. 151), una vez que asomaron los símbolos, se produjeron emociones relacionadas a los diferentes recuerdos junto a ese elemento, como se puede observar en la Figura 2.

Figura 2: Escenario intitulado "Agua es vida" - A) simbolización de personas; B) simbolización del ambiente marino C) simbolización de la biodiversidad.

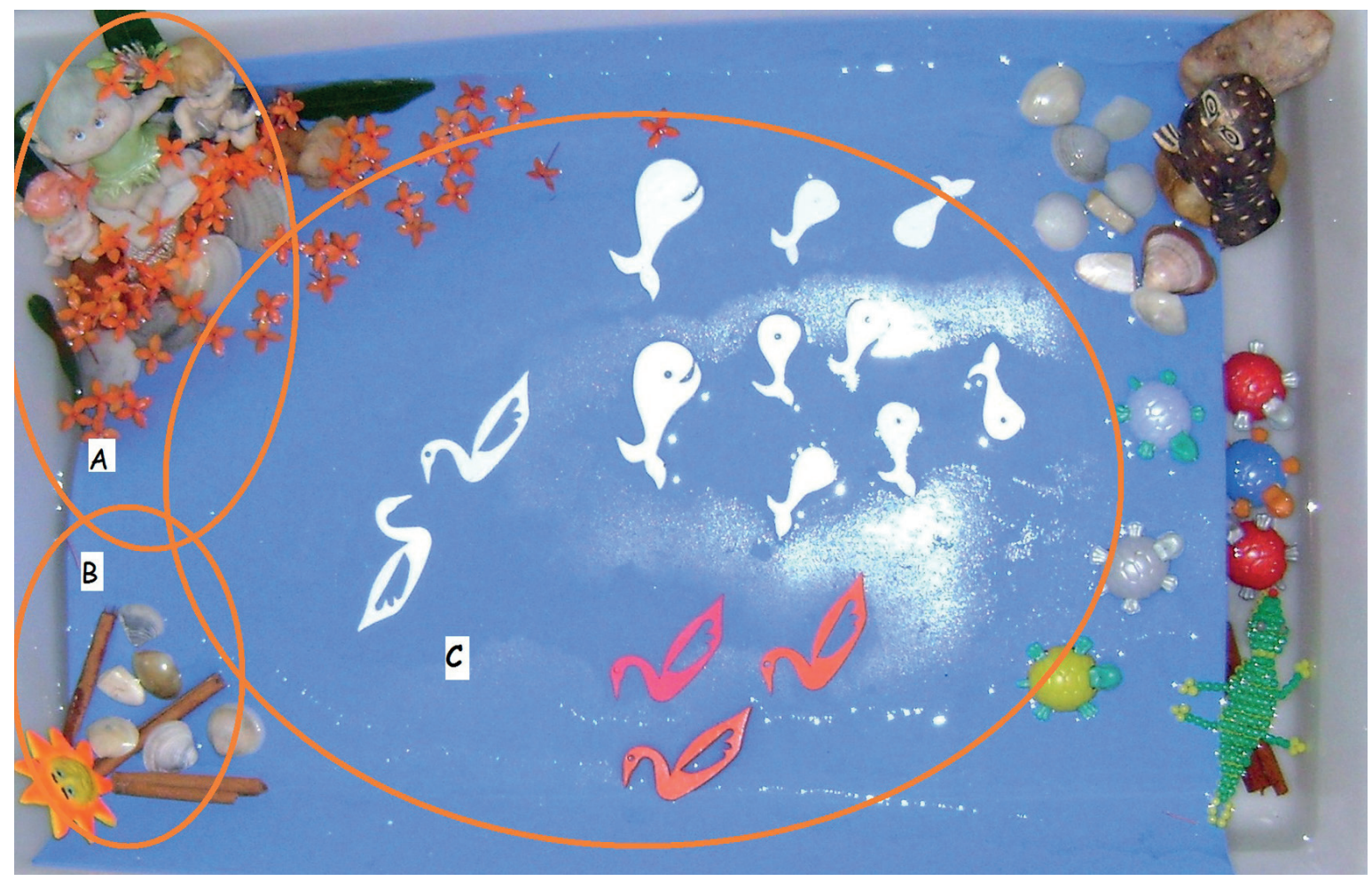

Fuente: archivo de la investigación. 
Con el paso de los años, al empezar la juventud/vida adulta, frente a las nuevas y cada vez más consciente lecturas mundo (Freire, 2012), frente a las relaciones que se establecían entre naturaleza/sociedad/ambiente (Loureiro, 2011), era perceptible la discriminación con respecto a los individuos con comportamientos típicos de los campesinos, tanto los que vivían como los que no vivían en regiones rurales. Ellos, por su parte, siempre que posible, negaban y ocultaban sus raíces campesinas, porque el comportamiento y los valores aceptados en esta sociedad urbanizada se relacionaban mucho más con la modernidad, debido al modelo de desarrollo adoptado en Brasil. De esta forma, se establecieron nuevas relaciones con la tierra, fuertemente orientadas por el consumo y el descarte, provocando una ceguera ambiental (Guattari, 2012).

Pero el destino encuentra formas sutiles de actuar y mostrar caminos, y durante el desarrollo profesional, escogimos algo que nos traía el mismo placer que se sentía en los "patios encantados" de las ecovivencias de la infancia y de la adolescencia. Así, elegimos la docencia de Ciencias y Biología. La Figura 3 muestra ese ardor presente en el llamado de la vocación, en el cual "una chispa que salta del humo es suficiente para impulsarnos a nuestro destino" (Bachelard, 2008, p. 28). Según el autor, el fuego hace que intuiciones personales y experiencias científicas se confundan por ser un objeto inmediato y con valor fenomenológico al actuar en una zona objetiva impura.

Figura 3: Escenario intitulado "La llama de la educación”. A): la energía, que simboliza la Heteroformación; B) el búho, que simboliza la Autoformación; C) las velas, que simbolizan la Ecoformación

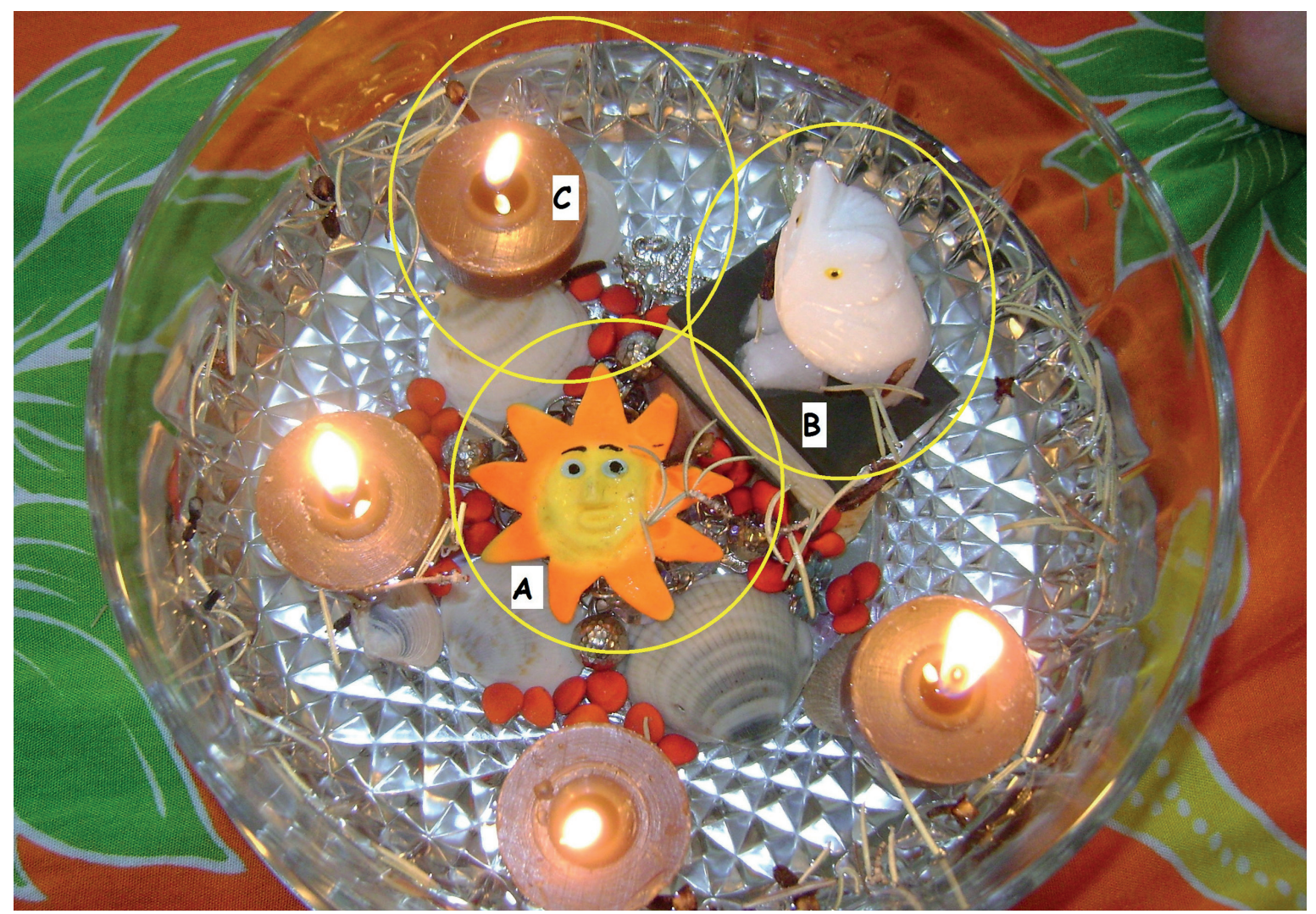

Fuente: archivo de la investigación. 
En los primeros años de docencia, prevaleció la forma 'artesanal' (Pimenta, Lima, 2004), pero sabía que era necesario superar los varios espacios en blanco que existían para ejercer reflexivamente la profesión. Entonces buscamos soporte epistemológico y metodológico para transponer nuestra forma 'artesanal' y alcanzar una práctica educacional reflexiva, porque "en la naturaleza, todo se encuentra en perpetuas oscilaciones de dilatación y contracción debido a la acción del fuego sobre los cuerpos" (Bachelard, 2008, p. 121). Iniciamos el contacto con varios cursos de corta y larga duración, tanto lato-sensu como stricto-sensu, consciente de que la formación no se construye solamente con el acúmulo de cursos, conocimientos y técnicas, como indica Nóvoa (2009). Así que, al profundizar los estudios acerca de la Educación Ambiental (EA) y, más específicamente, sobre su vertiente crítica (EAC), ${ }^{7}$ al percibir tales cambios en nuestra trayectoria como profesora de Ciencias Biológicas, había la premisa de transmitir a los estudiantes conocimientos basados no solo en los aspectos cognitivos, inherentes a esa área de enseñanza. Buscábamos también estimular las lecturas de mundo, dirigidas hacia el habitar sostenible, con la toma de decisiones y acciones corresponsables. En suma, era necesario desarrollar en los estudiantes aspectos de la autoformación, de la heteroformación y de la ecoformación (Pineau, 2008a).

Un nuevo espacio, también 'encantado', empezó a crearse, dado que que "en el trayecto que nos hace regresar a los orígenes, hay primeramente el camino que nos hace volver a la infancia, a nuestra infancia soñadora" (Bachelard, 2003, p. 94). Así, a los pocos las ecovivencias sobresalientes de la fase infantil y de la juventud pudieron ser experimentadas nuevamente en un ambiente escolar, ahora bajo la condición de profesora. Utilizando como referencias el lenguaje de la naturaleza de Capra (2012), la ecopedagogía de Gutiérrez e Prado (2008), la biología del amor de Maturana (2011) y la concepción libertaria de la Educación de Freire (2011), varios proyectos educacionales han sido creados y ecovivenciados, como se puede ver en la Figura 4, lo que está simbolizado a través del elemento tierra. Las clases, por su parte, traspasaban los límites de las cuatro paredes de un aula. Cualquier espacio era lugar para el aprendizaje significativo, según la concepción de la transgresión de espacios apuntada por Espírito Santo (1996), ya sea tal espacio formal o informal.

Los recuerdos fluían libremente con el Juego de Arena y las Escrituras de sí, desvelando reminiscencias y nuevas percepciones de ese proceso de ecoformación. Estaban en conformidad con Pineau (2008a, p. 52) cuando este afirmó que "el habitar no es solamente formado por hábitos que son más o menos un reflejo del alojarse; habitar exige nuevos aprendizajes y se convierte en una competencia individual y colectiva para construir y aprender". Por lo tanto, ya no observábamos la harmonía en el entorno ambiental como la habíamos ecovivenciado en la infancia. Lo que veíamos entonces era el crecimiento de un gran centro urbanizado e industrializado ${ }^{8}$, pero sin una planificación sostenible que fuera suficiente para las demandas de infraestructura de una población cada vez más grande. Tanto con respecto al cinturón de pobreza de las periferias, privado del debido saneamiento básico y sin una solución adecuada para que se descarten los desechos sólidos y orgánicos producidos, como con relación a las áreas de protección como nacientes, manglares y bosques de galería, e incluso con relación al descarte en el aire de cuerpos hídricos de residuos industriales no biodegradables.

Con la criticidad cada vez más latente de mi desarrollo en cuanto docente, entendía que el proceso educacional ocurría, como indica Freire (2011), cuando se comparten varios saberes oriundos de todos aquellos involucrados, tanto estudiantes como familiares, gestores y docentes, con la construcción de espacios sanos para un aprendizaje significativo. Pero la realidad observada era otra, caracterizada por la rigidez espacial de los ambientes pedagógicos, reafirmando en los estudiantes una ceguera ambiental. La ecovivencialidad (Schulz, 2014), 
la creatividad, la sensibilidad y la expresividad, además de la emancipación que buscaba la autoformación (Pineau, 2008b), no tenían un espacio ni recibían una valoración adecuados. Las relaciones entre esos estudiantes, que tenían como objetivo la heteroformación (Pineau, 2008a), eran marcadas por la falta de respeto, por la competencia y por la falta de solidaridad. De la misma forma, sus relaciones con el medio más inmediato, con su entorno, lo que objetivaba su ecoformación (Pineau, 2008a), no eran diferentes, porque eran orientadas por la lógica mercantilista-exploratoria, por la tendencia al consumo y al descarte.

Figura 4: Escenario intitulado "Las semillas de la educación”. A) simbolización de la escuela; B) simbolización de la comunidad escolar; C) simbolización del árbol-madre y sus semillas; D) simbolización de las mudas del nuevo plantío

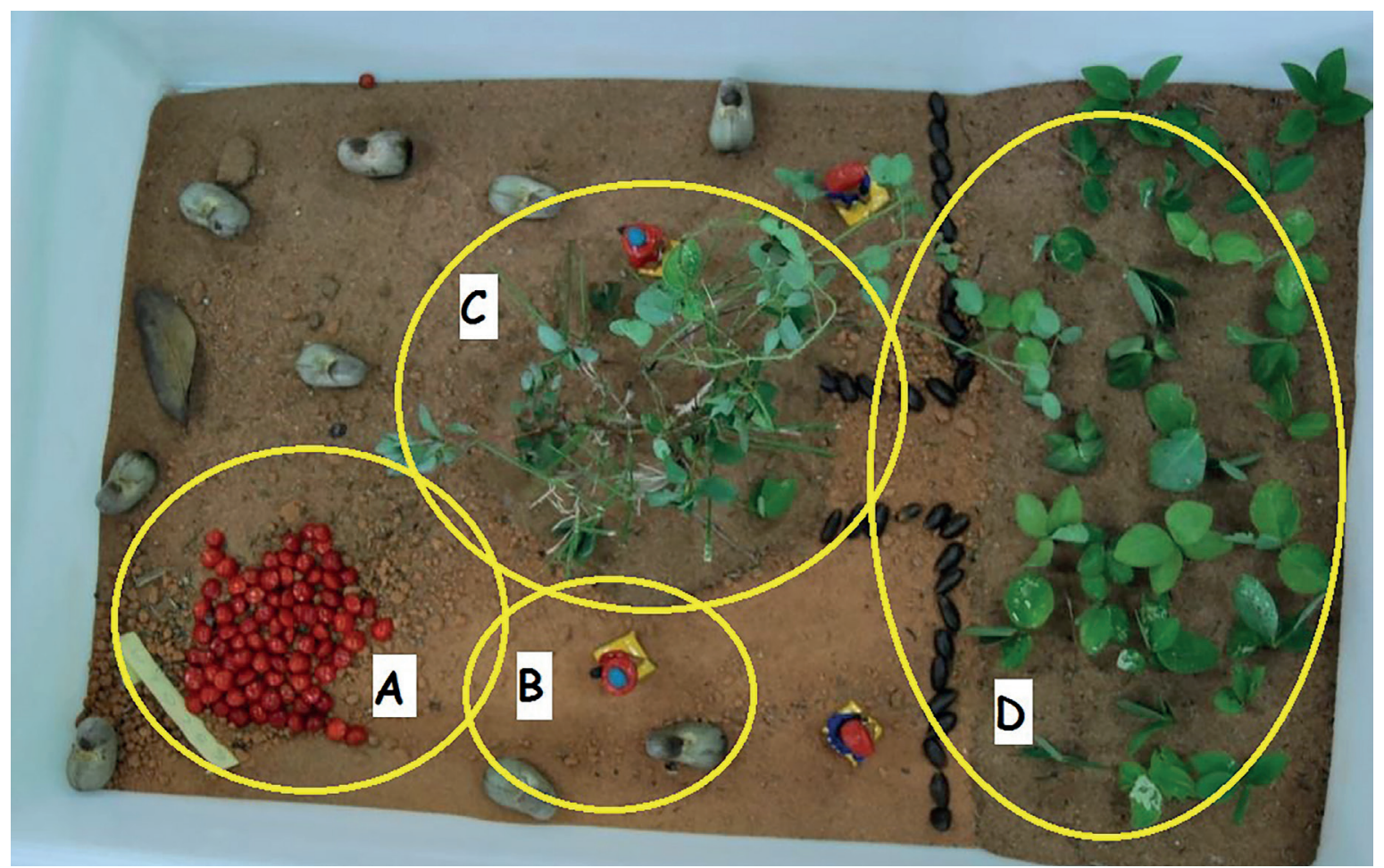

Fuente: archivo de la investigación.

La EA, por su parte, cuando era abordada por los docentes y gestores, tanto en el ambiente interno como en el ambiente externo de la institución, era limitada y poco eficiente, ya que no hacía que se examinaran cuestiones y valores sociales. No estimulaba la capacidad crítica, dado que que estaba concentrada en el objetivo de comunicar a la sociedad su eficiencia y preocupación ambiental según una lógica neoliberal y productivista (Gentili, 1995). Por lo tanto, era practicada como si el ser humano no fuera parte del ambiente, como si no fuera un ser natural, no ofreciendo intervenciones socioambientales. En otras palabras, la EAC no era contemplada.

Durante las clases con las ecovivencias, había otras observaciones inquietantes. Entre ellas, la desconexión de los alumnos urbanos con la tierra, con ambientes naturales, teniendo en cuenta que ellos evitaban tocar la tierra para no 'ensuciarse'. En las caminatas por el bosque, mostraban falta de equilibrio y de coordinación motriz, ansiedad y miedo, no logrando que- 
darse en silencio o apreciar los sonidos, olores y colores del 'nuevo ambiente'. Si habían sido creados en lugares planos, 'limpios', con aspecto de modernidad, ¿cómo iban a sentir y manifestar placer y desenvoltura en la interacción con un 'patio encantado'? Por otro lado, observábamos el comportamiento de los hijos de campesinos de las áreas rurales dentro de la ciudad, que demostraban, además de tranquilidad, cuidado, cariño $y$ afecto en esas ecovivencias con relación al medio y a los demás. Esas observaciones estaban en conformidad con Tuan (2012) y el principio de la topofilia. Para el autor, ese término es un neologismo que incluye todos los vínculos de afectividad de los seres humanos con su entorno más inmediato, o sea, con su medio ambiente.

Frente a esas inquietudes, durante tal trayectoria en cuanto docente, varios retos han surgido, retos que estimulaban a crear un lugar de ecovivencias, de reconexión, donde fuera posible para los participantes el reencantamiento con los 'patios encantados' de nuestra infancia y que dialogarán con los saberes académicos científicos de la EAC. Se sentía la necesidad de seguir profundizando los estudios, asociando la enseñanza de Ciencias y Biología, la EAC y las relaciones Ecoformativas. Esa intención fue simbolizada en la Figura 5: "gracias al método del Juego de Arena, las dimensiones espiritual y psicológica no son solamente consteladas en el individuo, sino que al mismo tiempo se les da una forma concreta a través del trabajo manual" (Ammann, 2004, p. 11). Ese es el potencial que contiene el espacio simbólico de la caja de arena ( $\mathrm{Scoz}$, 2011). Así que era necesario provocar nuevas polinizaciones en nuevos aires, y así elegimos el colibrí para tal simbolización, para ese encuentro entre sujeto y objeto, entre emoción y pensamiento, entre consciente e inconsciente.

Nos mudamos de Santa Catarina, estado de la región Sur de Brasil, y nos trasladamos a la otra extremidad del país, a la capital del estado de Rio Grande do Norte, la ciudad de Natal. En ese nuevo 'patio', el ambiente observado es un poco diferente en varios aspectos: por su biodiversi- dad, con sus dunas; por la expresión cultural, con sus creencias y valores; o aún por el modo cómo se relacionan las personas con ellas mismas y con su medio. "Desraizar exige violencia, provocaciones, gritos", como afirma Bachelard (2003, p. 229). Así que, en conformidad con Pineau (2008a, p. 55) cuando nos dice que "es necesario mucho tiempo y energía para encontrar un otro lugar para re-enraizarse", estábamos conscientes de que sería necesario recomenzar todo nuevamente en un 'patio' que no conocíamos, que era extraño para nosotros.

$\mathrm{Y}$ en ese proceso de creación de nuevas raíces, observábamos también en los habitantes de la nueva ciudad comportamientos de estigmatización y desprecio con relación a las familias oriundas del campo, más precisamente del "semiárido potiguar" (la región semiárida del Rio Grande do Norte), una región que sufre constantemente con la falta de lluvias y que tiene un bajo régimen pluviométrico. Esas impresiones nos hacían volver a los recuerdos de nuestra región y a la marginalización que también ocurría con nuestros estudiantes del campo. Además, era necesario resignificar las ideas que fueran incorporadas a lo largo de la vida, de que el suelo de la región Noreste del país sería infértil $^{9}$, y con ese objetivo probamos a sembrar un huerto en esa nueva y diferente tierra. Como elemento de deconstrucción, hemos percibido una latente fertilidad, dado que en poco tiempo surgieron los primeros brotes.

La necesidad de investigar la Enseñanza de Ciencias y Biología, la EAC y las relaciones Ecoformativas aún nos intrigaban, llevándonos a buscar sitios e investigaciones que dialogaran con nuestra problemática. En el grupo de investigación BACOR-PPGE-UFRN, encontramos el primer espacio académico, con estudios e investigaciones que consolidan este artículo. Con enfoque en la corporeidad y la expresividad, la línea de investigación elegida también se ocupaba de la importancia atribuida al enfoque vivencial humanitario (Cavalcanti, 2010) utilizando como recursos el Juego de Arena y las Escrituras 
de sí. De esta forma, se ofrecía una nueva metodología para incorporarse al proceso de formación de los profesores-investigadores. Esta perspectiva educacional invierte en la formación a partir del propio sujeto y su vivencia, que se apoya en los estudios acerca de los fenómenos humanos de la creatividad, de la implicación, de la autorreflexión y de la sensibilidad para que se incorporen a los nuevos saberes y a las nuevas prácticas educacionales (Cavalcanti, 2010).

Figura 5: Escenario intitulado 'Vida nueva, nuevos aires'. En (A), simbolización de la apertura para nuevas investigaciones. En (B), simbolización de encuentro con el colibrí

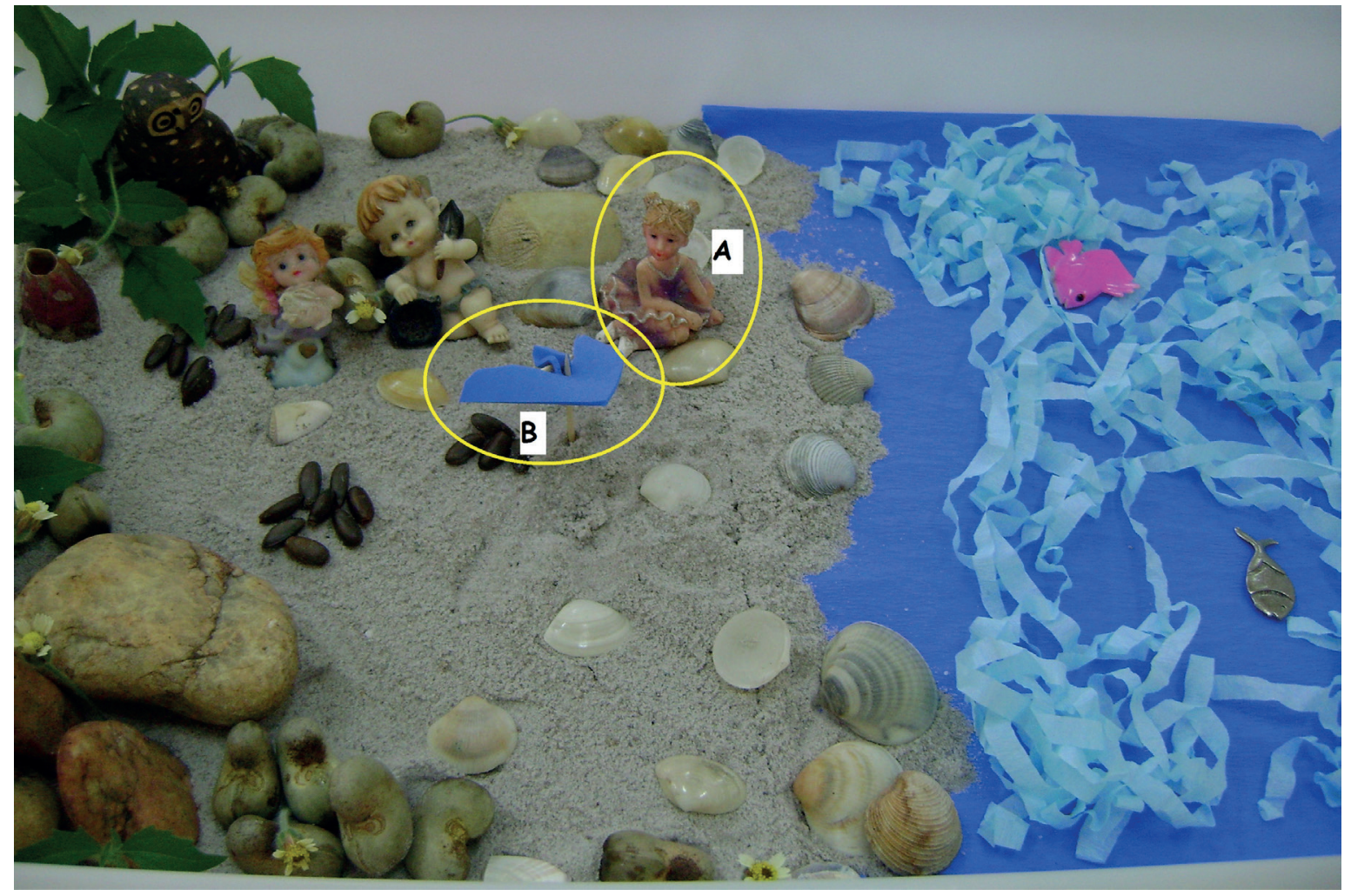

Fuente: archivo de la investigación.

Frente a todo ese trayecto ecoformativo, al final del 2014, materializamos parte de nuestras inquietudes, porque según Bachelard (2013, p. 120), "cuando amamos una realidad con toda el alma, es porque nuestra realidad es ya un alma”. Así, defendimos la tesis intitulada 'Pedagogia Ecovivencial: por uma Educação Ambiental Emancipatória', (Schulz, 2014) convalidada como estrategia pedagógica de EAC. Tal propuesta se apoya sobre tres ejes fundadores: el epistemológico, el ontológico y el metodológico. Para el eje epistemológico, la propuesta fue fundada con los siguientes aportes teóricos: la Biología del Amor (Maturana, 2010, 2011), sobre la cual se basó la vertiente de la afectividad, la Ecopedagogía (Gutiérrez; Prado, 2008), sobre la cual se basó la ecovivencialidad, y la Concepción Crítica y Libertaria de la Educación (Freire, 2011, 2012), sobre la cual se basó la vertiente de la emancipación, de la criticidad. El eje metodológico se basó en los aspectos conceptuales, procedimentales y actitudinales (Coll et al., 2000) inherentes al proceso de enseñanzaaprendizaje, fundamentales para la formación integral. Finalmente, el eje ontológico se basó en el proceso (auto-hetero-eco)formativo de Pineau 
(2008a). Por fin, con el objetivo de seguir con ese proceso de materialización, esperamos difundir esta propuesta pedagógica, ofreciéndola para aplicaciones en otros públicos para que pueda ser probada, criticada y corregida a través de diálogos provechosos entre nosotros, educadores, en busca de la EAC que queremos.

\section{Consideraciones finales}

Asociar conocimientos de la investigación (Auto)biográfica y del Juego de Arena, o "Sandplay", en cuanto recursos metodológicos autorreflexivos fue fundamental para comprender mejor el sentido de nuestra ecoformación. El Juego de Arena posibilitó el flujo de emociones y sentimientos represados con la creación de imágenes internas. A través de las escrituras de sí, fuimos llevados a reflexionar, a expresar y a resignificar lo que sentimos, lo que hacemos, lo que pensamos y hacia dónde caminamos.

Además, el reto de escribir este ensayo nos hizo conscientes de que la ecoformación ha sido el hilo conductor de toda nuestra trayectoria personal, docente y académica. Nos hizo ver que estamos en un punto privilegiado de nuestra trayectoria, en el cual la intuición encontró los fundamentos teóricos necesarios para actuar de forma madura y global. Nuestras frecuentes visitas a las playas del Rio Grande do Norte nos hicieron recordar, entre baños de mar, la clásica explicación de Bourdieu (1998) sobre el capital cultural. Ese capital que, diferente de los capitales financiero y económico, no se puede obtener rápidamente, por herencia o ganando en la lotería, por ejemplo. Al contrario, así como un bronceado de verano, surge lentamente, inscribiendo sobre la piel un nuevo color, capa sobre capa. Sentimos que ese bronceado alcanzó su punto ideal, sentimos ese nuevo capital cultural y así empezamos a apropiarnos de él.

Esperamos, entonces, que este texto, cuyo referencial metodológico es el Juego de Arena y las Escrituras de sí, termine por promover discusiones fundamentales y amplíe el debate en la comunidad, estimulando la autoformación, la heteroformación y la ecoformación para que se obtenga una EAC ecovivenciada, amorosa y emancipadora.

\section{Notas}

1 Adoptamos las contribuciones de González Rey (1997) sobre el concepto de subjetividad, el cual, según el autor, se compone de la psique en el sujeto individual, formándose también de procesos y estados que son inherentes a ese individuo en sus actividades de acción social.

2 La formación humana, según Pineau, ocurre de forma tripolar: entre la acción del individuo con sí mismo (autoformación), del individuo con los demás (heteroformación) y del individuo con el medio ambiente (ecoformación).

3 "Base da Corporeidade" (BACOR) del Programa de Posgrado en Educación de la Universidad Federal del Rio Grande do Norte.

4 Todos los registros eran hechos por medio de un portafolio con las Escrituras de sí que evidenciaban marcas acerca de los procesos de ecoformación de la autora.

5 La ecovivencialidad deriva de dos palabras: "oikos" (que en griego significa "casa") y "vivencialidad", que se refiere a la vivencia y significa sentir o experimentar algo con intensidad.

6 Decimos "patios encantados" |"quintais encantados", en el original) a los sitios con potencial ecoformador.

7 La Educación Ambiental Crítica (EAC) es parte de la macrotendencia crítica propuesta por Layrargues y Lima (2014), reuniendo corrientes de la Educación Ambiental Popular, Emancipadora, Transformadora y en el Proceso de Gestión Ambiental.

8 La ciudad de Joinville (SC), durante los 70 y los 80, presentó un rápido proceso de industrialización, pasando a ser conocida como la "Manchester Catarinense", en referencia a la gran ciudad industrializada de Inglaterra.

9 Maknamara (2012) apunta que, históricamente, hay una red de discursos que han estado contribuyendo para la incorporación de ciertas ideas acerca de la región Noreste de Brasil, y entre ellas está la idea de la infertilidad del suelo.

\section{Bibliografía}

Ammann, R. (2004). A terapia do jogo de areia: imagens que curam a alma e desenvolvem a personalidade. Tradução de Marion Serpa. $2^{\text {a }}$. ed. São Paulo: Paulus.

Bachelard, G. (1985). O novo espirito científico. Tradução de Juvenal Hahne Junior. 2a ed. Rio de Janeiro: Tempo Brasileiro.

Bachelard, G. (2001). O ar e os sonhos: Ensaio sobre a imaginação do movimento. Tradução de 
Antonio de Pádua Danesi. 2a ed. São Paulo: Martins Fontes.

Bachelard, G. (2003). A Terra e os Devaneios do Repouso - ensaio sobre as imagens da intimidade. Tradução de Paulo Neves. S. Paulo: Martins Fontes.

Bachelard, G. (2008). A psicanálise do fogo. Tradução de Paulo Neves. 3a ed. São Paulo: Martins Fontes.

Bachelard, G. (2013). A água e os sonhos - Ensaio sobre a imaginação da matéria. Tradução de Antonio de Pádua Danesi. 2a ed. São Paulo: Martins Fontes.

Bourdieu, P. (1998). Os três estados do capital cultural. In: Nogueira, Maria Alice; Catani, Afrânio (Org.). Escritos de educação (265-270). 2 da. ed. Petrópolis: Vozes.

Capra (2012). A Teia da Vida. 13a ed. São Paulo: Cultrix.

Cavalcanti, K. B. (2010). O jogo de Areia como obra de arte da vida. In Cavalcanti, K. B. (Orgs.), Jogo de Areia: uma abordagem transdisciplinar para a Educação (19-48). Natal, RN: EDUFRN.

Coll, C. et al. (2000). Os conteúdos na reforma. Porto Alegre: Artmed.

Espírito Santo, R. C. (1996).Pedagogia da Transgressão: um caminho para o autoconhecimento. $10^{\mathrm{a}}$ ed. São Paulo: Ágora.

Freire, P. (2011). Pedagogia do Oprimido. 50. ed. Rio de Janeiro: Paz e Terra.

Freire, P. (2012). À Sombra desta Mangueira. 10a ed. Rio de Janeiro: Civilização Brasileira.

Gadotti, M. (2000). Pedagogia da Terra. 3. ed. São Paulo: Peirópolis.

Guattari, F. (2012). As três ecologias. 21 a edição. São Paulo: Papirus.

Gatti, B. (2003). Formação continuada e professores: a questão social. Cadernos de Pesquisa, 119, (191-204).

Gentili, P. (1995). Como reconhecer um governo neoliberal? Um breve guia para educadores. In Silva, L. H.; Azevedo, J. C. (Orgs.), Reestruturação curricular: teoria e prática no cotidiano da escola (128-137). Petrópolis: Vozes.

González Rey, F. (1997). Epistemología cualitativa y subjetividad. São Paulo: Educ.

Gutiérrez, F., \& Prado, C. (2008). Ecopedagogia e Cidadania Planetária. 4a ed. São Paulo: Instituto Paulo Freire.
Kalff, D. M. (1980). A psychotherapeutic approach to the psyche. 2a ed. Boston: Sigo.

Layrargues, P. O. \& Lima, G. F. C. (2014). As macrotendências político-pedagógicas da Educação Ambiental brasileira. Ambiente \& Sociedade, XVII(1), 23-40.

Loureiro, C.F. (2011). Educação ambiental e os movimentos sociais na construção da cidadania ecológica e planetária. In Loureiro, C. F; Layrargues, P. P.; Castro, R. S. (Orgs.), Educação Ambiental: repensando o espaço da cidadania (73-103). São Paulo: Cortez.

Maknamara, M. (2012). Educação ambiental e Nordestinidade: Desafios à práxis ecologista. Revista Brasileira de Educação Ambiental, (10-17). Rio Grande, Número Especial.

Maturana, H. (2010). A árvore do conhecimento: as bases biológicas da compreensão humana. São Paulo: Palas Athena.

Maturana, H., Zoller, G. V. (2011). Amar e Brincar: fundamentos esquecidos do humano. Tradução Humberto Mariotti e Lia Diskin. 3. ed. São Paulo: Pala Atenas.

Nóvoa, A. (2002). Formação de professores e trabalho pedagógico. Lisboa: Educa.

Nóvoa, A. (2009). Professores: imagens do futuro presente. Lisboa: Educa.

Passeggi, M. C. (2008). Memoriais auto-bio-gráficos: a arte profissional de tecer uma figura pública de si. In Passeggi, M. C., Barbosa, T. M. N. (Org.). Memórias, memoriais: pesquisa e formação docente. 1ra. ed. São Paulo: Paulus; EDUFRN.

Passeggi, M. C. (2010). Narrar é humano! Autobiografar é um processo civilizatório. In Passeggi, M. C., Silva, V. B. (Org.), Invenções de vidas, compreensão de itinerários e alternativas de formação (103-130). São Paulo: Cultura Acadêmica.

Pimenta, S. G.; Lima, M. S.L. (2004). Estágio e Docência. São Paulo: Cortez.

Pineau, G. (2004). Temporalidades na formação: rumo a novos sincronizadores. São Paulo: Triom.

Pineau, G. (2008a). Aprender a habitar a Terra: ecoformação e autobiografias ambientais. In Passeggi, M. C. Souza, E. C. S. (Org.), (Auto) biografia: formação, territórios e saberes (4766). São Paulo: Paulus. 
Pineau, G. (2008b). O "gaio saber" do amor à vida. In Souza, E. C.; Mignot, A. C. V. (Orgs), Histórias de vida e formação de professores (17-38). Rio de Janeiro: Quartet.

Pineau, G. (2010). A autoformação no decurso da vida: entre a hetero e a ecoformação. In Nóvoa, A.; Finger, M. (orgs): O método (auto) biográfico e a formação (98-118). São Paulo: Paulus.

Pineau, G., \& Le Grand, J. (2012). As histórias de vida. Tradução Carlos Eduardo Galvão Braga e Maria da Conceição Passeggi. Natal: EDUFRN.

Placco, V.M.N.S. (2002). Relações interpessoais na sala de aula e desenvolvimento pessoal. Em Almeida, L.R. e Placco, V.M.N.S. (Eds.), As relações interpessoais na formação de professores (7-19). São Paulo: Loyola.

Schulz, L. (2014). Pedagogia Ecovivencial: por uma educação ambiental emancipatória. Tese (Doutorado) - Programa de Pós-Graduação em Educação. Universidade Federal da Paraíba, João Pessoa.

Scoz, B. J. L. (2011). Identidade e subjetividade de professores - sentidos do aprender e do ensinar. Petrópolis/RJ: Vozes.

Tuan, Y. (2012). Topofilia: um estudo da percepção, atitudes e valores do meio ambiente. Londrina/ PR: EDUEL.

Weinrib, E.L. (1993). Imagens do self: o processo terapêutico na caixa-de-areia. Tradução de David Gilbert Aubert. São Paulo: Summus. 
